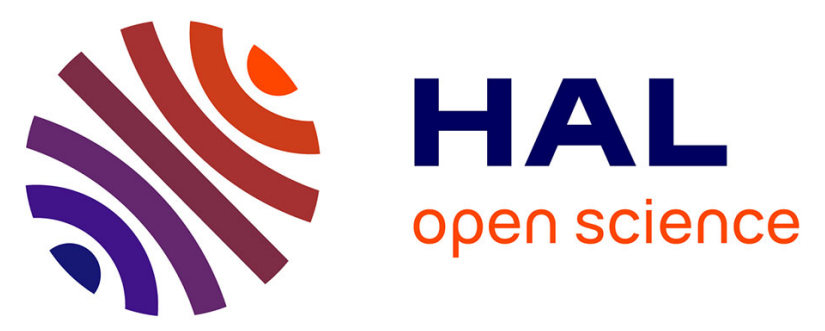

\title{
Playing with Pt II and Zn II Coordination to Obtain Luminescent Metallomesogens
}

Adelina-antonia Andelescu, Benoît Heinrich, Maria Angela Spirache, Emilie

Voirin, Massimo La Deda, Giuseppe Di Maio, Elisabeta Szerb, Bertrand Donnio, Otilia Costisor

\section{To cite this version:}

Adelina-antonia Andelescu, Benoît Heinrich, Maria Angela Spirache, Emilie Voirin, Massimo La Deda, et al.. Playing with Pt II and Zn II Coordination to Obtain Luminescent Metallomesogens. Chemistry - A European Journal, 2020, 26 (21), pp.4850-4860. 10.1002/chem.202000124 hal-03007362

\section{HAL Id: hal-03007362 https://hal.science/hal-03007362}

Submitted on 3 Jan 2021

HAL is a multi-disciplinary open access archive for the deposit and dissemination of scientific research documents, whether they are published or not. The documents may come from teaching and research institutions in France or abroad, or from public or private research centers.
L'archive ouverte pluridisciplinaire HAL, est destinée au dépôt et à la diffusion de documents scientifiques de niveau recherche, publiés ou non, émanant des établissements d'enseignement et de recherche français ou étrangers, des laboratoires publics ou privés. 


\section{Playing with $\mathrm{Pt}^{\mathrm{II}}$ and $\mathrm{Zn}$ "Coordination to Obtain Luminescent Metallomesogens}

Adelina-Antonia Andelescu, Benoît Heinrich, Maria Angela Spirache, Emilie Voirin, Massimo La Deda, Giuseppe Di Maio, Elisabeta I. Szerb*, Bertrand Donnio*, Otilia Costisor*

Cite as Chem. Eur. J. 2020, 26, 4850-4860

First published: 17 February 2020

https://doi-org.scd-rproxy.u-strasbg.fr/10.1002/chem.202000124

\section{Abstract}

Blue-green luminescent terpyridine-containing $\mathrm{Pt}$ " and $\mathrm{Zn} \mathrm{n}^{\prime \prime}$ complexes are reported. Equipped with lipophilic gallate units, which act as monodentate ancillary coordinating ligands and/or as anions, they display low-temperature mesomorphic properties (lamello-columnar and hexagonal mesophases for $\mathrm{Pt}^{\| \prime}$ and $\mathrm{Zn} \|$ complexes, respectively). The mesomorphic properties were investigated by polarised optical microscopy, differential scanning calorimetry, thermogravimetric analysis and X-ray scattering of bulk materials and oriented thin films. The model of self-assembly into the lamello-columnar phase of the Pt" complex has been described in detail. The optical properties of the complexes were investigated in the liquid and condensed liquid crystalline states, highlighting the delicate balance between the role of the metal in determining the type of excited state responsible for the emission, and the role of the ancillary ligand in driving intermolecular interactions for proper mesophase formation.

\section{Introduction}

Luminescent d-block metallomesogens are promising functional materials for practical applications. They have mainly been investigated in terms of obtaining polarised emission to be used as backlighting in displays, $\underline{\mathbf{1}} \mathbf{\underline { 4 }}$ but also some studies concerning their use as stimuli responsive materials for sensing $\underline{\mathbf{5}}, \underline{\mathbf{6}}$ or security inks, $\underline{\mathbf{Z}}$ or high-hole mobility materials for electroluminescent devices $\underline{8}$ have been reported. Despite recent progress with square-planar $\mathrm{Pt}$ "l and octahedral Irll' complexes, which are considered among the best emitters, there is still considerable work to be done to control the phase type and transition temperatures or to improve the luminescence in the mesophase. $\underline{9}$ In fact, only a few studies on the mesophases of luminescent liquid-crystalline transition metal complexes have been carried out, with, just to cite non-exhaustively, the contributions of Bruce et al. on Ir'l', $\underline{\mathbf{8}}, \underline{\mathbf{1 0}} \underline{\mathbf{1 2}}$ Espinet et al. $\underline{\mathbf{1 3}}$ and Tsutsumi et al. $\underline{\mathbf{1 4}}, \underline{\mathbf{1 5}}$ on Au', Gimenénez et al. on $\mathrm{Ag}^{[116]}$ and $\mathrm{Zn} ", \underline{17}$ Cârcu et al. on Pd", $\underline{\mathbf{1 8}}$-20 Cano et al. on $\mathrm{Ag}^{[21-22]}$ and Pucci, Crispini and Ghedini et al. on $\mathrm{Ru}^{\prime \prime}, \underline{\mathbf{2 3}} \mathrm{Ag}^{\prime}, \underline{\mathbf{2 4}} \underline{\underline{26}} \operatorname{lr}^{\mathrm{rl|l}[2]]}$ and $\mathrm{Zn}^{11[28,29]}$ complexes. For practical applications, technological and economic issues have to be taken into account, such as thermal 
and optical stabilities, availability and cost of the precursors and straightforward syntheses. Lately, some ionic Pt" complexes with terpyridine (tpy) or functionalised terpyridine ligands were showed to be good candidates for obtaining luminescent supramolecular assemblies both in liquid crystalline phases and gels, ${ }^{[30-33]}$ owing to the extended aromatic region that favours $\pi-\pi$ stacking and short Pt...Pt distances. ${ }^{[34]}$ However, no study has demonstrated the retention of luminescence properties in the mesomorphic ranges of the bulk Pt" terpyridine-based complexes yet.

In this context, our interest in luminescent $d$-block metallomesogens ${ }^{[24,27,35-37]}$ prompted us to synthesise some luminescent Pt" coordination complexes. They were prepared by a versatile and straightforward synthesis, which permits facile molecular engineering by using anions of different coordination strengths and dimensions, including non-coordinating medium sized $\mathrm{BF}_{4}$, weakly coordinating bulky lipophilic benzoate and small and strongly coordinating $\mathrm{Cl}$ (Scheme 1 ). This strategy represents an easy way to induce liquid crystallinity in $\mathrm{Pt}^{\prime \prime}$ complexes by avoiding the several steps necessary to precisely functionalise the ligands. To explore the role of the metal cation, the same strategy was extended to $\mathrm{Zn}^{\prime \prime}$ complexes, but owing to the different electronic configuration only neutral penta-coordinated species were obtained.

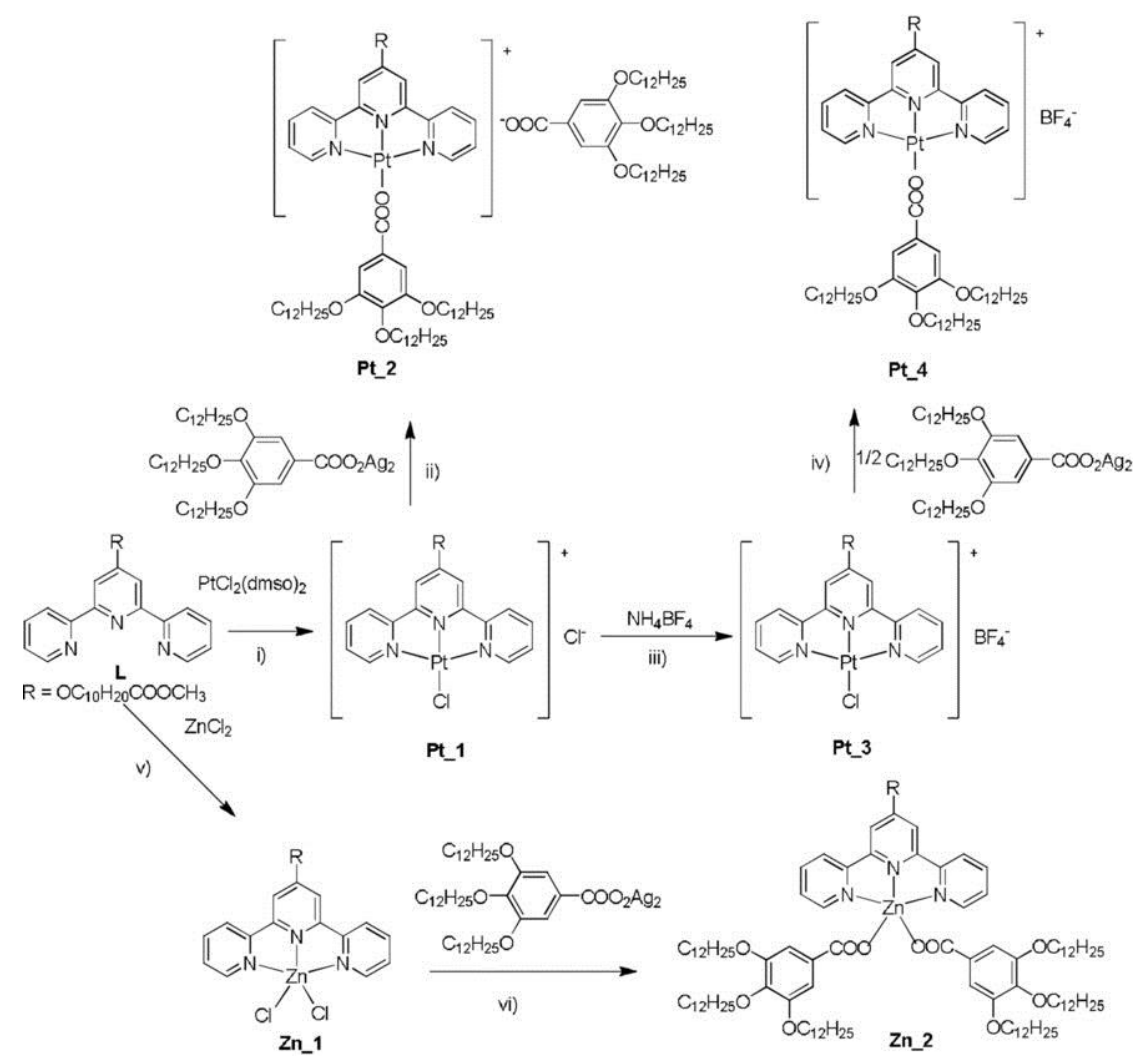

Scheme 1 Synthesis of Pt" and $\mathrm{Zn}$ " complexes: i) $\mathrm{MeOH}, \Delta T, 1.5 \mathrm{~h}$; ii) $\mathrm{CHCl}_{3} / \mathrm{MeOH} 1: 1$, r.t., $2 \mathrm{~h}$; iii) $\mathrm{CHCl}_{3} / \mathrm{MeOH} 1: 1$, r.t., 1 h; iv) $\mathrm{CHCl}_{3} /$ acetone 1:5, r.t., 2 h; v) $\mathrm{MeOH} / \mathrm{CHCl}_{3}$, r.t., 1.5 h; vi) $\mathrm{CHCl}_{3}$, r.t., $2 \mathrm{~h}$.

In this study, we designed and synthesised tpy-containing $\mathrm{Pt}$ " and $\mathrm{Zn}$ " complexes by using this simple concept. Initially, the straight, non-functionalised 2,2':6',2“-terpyridine ligand was used, but 
the low solubility of the Pt" chloro chloride (analogues of Pt_1 in Scheme $\mathbf{1}$ ) and $\mathrm{Zn}$ " dichloro (analogues of $\mathbf{Z n \_ 1 ) ~ d e r i v a t i v e s ~ p r e v e n t e d ~ t h e ~ a c c e p t a b l e ~ p r o g r e s s ~ o f ~ t h e ~ s u c c e s s i v e ~ s t e p s . ~}$ Therefore, the ligand was functionalised with a long alkyl chain through an ether linkage (ligand $L$ ). The methyl ester group at the end of the chain is important for future applications of the complexes, as it allows derivatisation potentially to link the complexes onto functionalised metallic and/or oxide nanoparticles or mesoporous silica structures for theranostic purposes, in particular.

Of the three lipophilic complexes (i.e., Pt_2, Pt_4, Zn_2 in Scheme 1), two were found to be mesomorphous, displaying room-temperature lamello-columnar (Pt_4, LamColr and Lamcol) and hexagonal columnar (Zn_2, Colnex) phases, whereas Pt_2 was found to be thermally unstable and to dissociate rapidly (see below). The thermal behaviour and liquid-crystalline self-assemblies were fully characterised by polarised optical microscopy (POM), differential scanning calorimetry (DSC), thermogravimetric analysis (TGA) and small- and wide-angle X-ray scattering (S/WAXS) of bulk materials, combined with grazing incidence wide-angle X-ray scattering (GIWAXS) on oriented thin films. Accurate structural and photophysical investigations in different solvents and condensed states were carried out, in an attempt to determine structure-property relationships. In particular, of capital interest was the investigation of the influence of the mesophase organization on the emitting states.

\section{Results and Discussion}

\section{Synthesis and spectroscopic characterisation}

Ligand $\mathbf{L}$ (tpy) was obtained from 2,6-bis-(2'-pyridyl)-4-pyridone ${ }^{[38]}$ by etherification with methyl 11 bromoundecanoate ${ }^{[39]}$ (see the Supporting Information). Complex Pt_1, synthesised by a slight modification of a method described in the literature for similar derivatives, ${ }^{[40]}$ was used as precursor for both Pt_2 and Pt_3 ionic complexes: Pt_2 was obtained by reacting Pt_1 with 2 moles of the silver(I) salt of 3,4,5-tridodecyloxybenzoate, ${ }^{[41]}$ whereas Pt_3 was obtained by metathesis reaction by using an excess of $\mathrm{NH}_{4} \mathrm{BF}_{4}$. The intermediate coordination strength of the benzoate unit gives the possibility for this anion to act as both counter anion and as coordinating ligand on Pt", when no other competitor is present (complex Pt_2), or exclusively as a ligand in the presence of a noncoordinating anion like $\mathrm{BF}_{4}$ (complex Pt_4).

The reaction of the tpy ligand $\mathbf{L}$ with $\mathbf{Z n C l}_{2}$ afforded the neutral complex $\mathbf{Z n} \_\mathbf{1}$, with the metal centre penta-coordinated by the tridentate terpyridine and two monodentate chlorine ligands. Although $\mathrm{Zn}^{\prime \prime}$ can be forced to accommodate a square-planar geometry with salicyldimine Schiff base ${ }^{[42,43]}$ or porphyrin ${ }^{[44]}$ ligands, without steric constraints, it prefers tetrahedral or higher number coordination

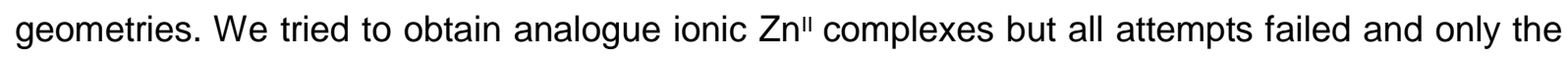


neutral Zn_2 complex was obtained with two benzoate ligands saturating the coordination sphere of the $\mathrm{Zn}$ "metal centre. The proposed chemical structures of the ligand and its $\mathrm{Pt}$ " and $\mathrm{Zn}$ " complexes are supported by IR and accurate 1D and 2D NMR spectroscopy. The ionic character of the Pt" complexes was evidenced in solution by conductivity measurements. ${ }^{[45]}$ The complexes were obtained as yellow ( $\mathrm{Pt}^{\prime \prime}$ species) or white ( $\mathrm{Zn}$ " species) powder or waxy solids and were dried for several days under high-pressure vacuum and then equilibrated under air. All $\mathrm{Pt}$ " complexes were hygroscopic; the presence of water molecules being evidenced both by IR spectroscopy (strong broad band centred at $3400 \mathrm{~cm}^{-1}$ ) and by TGA experiments (Figures SI-1 to SI-7 in the Supporting Information) and elemental analysis.

The first indication of the dual coordination mode of the benzoate group in the case of the Pt_2 complex was evidenced by the $\mathrm{COO}^{-}$stretching frequencies, different from the frequencies of the alkyl chain methanoate $\left(v_{\mathrm{as}}=1740 \mathrm{~cm}^{-1}\right)$. Indeed, for the benzoate the asymmetrical stretching $\left(v_{\mathrm{as}}\right)$ is around $1635 \mathrm{~cm}^{-1}$, and the symmetrical stretching $\left(v_{\mathrm{s}}\right)$ for the ionic band appears at $1555 \mathrm{~cm}^{-1}$ (Pt_2) and at $1340 \mathrm{~cm}^{-1}$ for a coordinated bond (Pt_2 and Pt_4), giving a separation $(\Delta)$ of 80 and $295 \mathrm{~cm}^{-1}$, respectively (Figure 1) ${ }^{[46]}$ Moreover, for Pt_4, the characteristic band of the $\mathrm{BF}_{4}{ }^{-}$counter ion appears centred at $1062 \mathrm{~cm}^{-1}$ (Figure 1). The IR spectra of the Zn" derivative Zn_2 (Figure SI_1, in the Supporting Information) contain only the stretching COO- vibrations corresponding to the coordinated specie $\left(\Delta \approx 250 \mathrm{~cm}^{-1}\right)$.

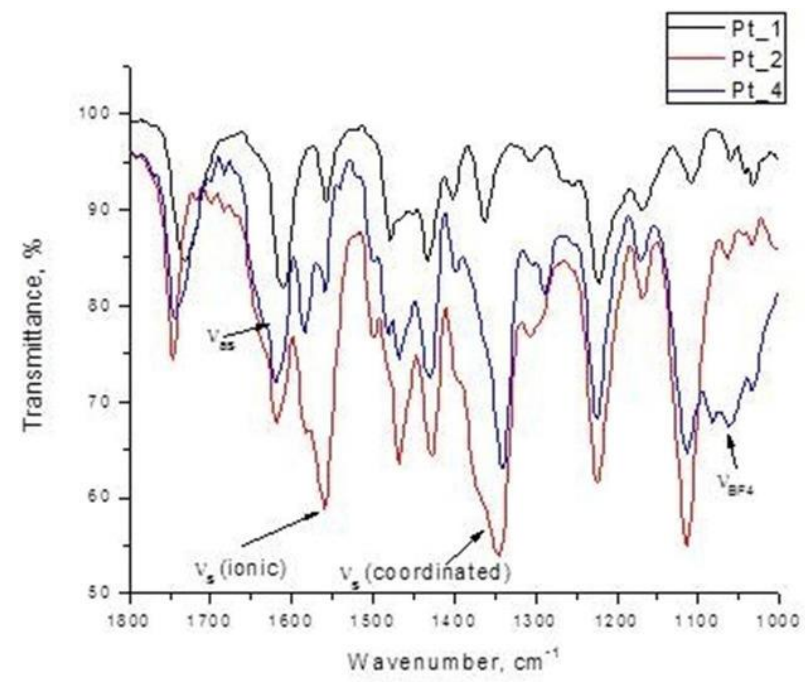

Figure 1 IR spectra of Pt" complexes Pt_1, Pt_2 and Pt_4, showing the two types of carboxylate coordination $\mathrm{m}$ odes.

The chemical shifts of the aromatic protons were assigned on the basis of accurate $1 \mathrm{D}$ and $2 \mathrm{D}$ NMR investigations (Tables SI- 1 to SI-6 in the Supporting Information). In the cases of Pt_2 and Pt_4, the aromatic protons belonging to the benzoate groups have different chemical shifts when coordinated to the metal centre as a monodentate ligand or ensure the neutrality of the 
complex as a negatively charged ion (Figure 2). In particular, for the coordinated benzoate, the aromatic protons are less shielded, shifting to higher frequencies.

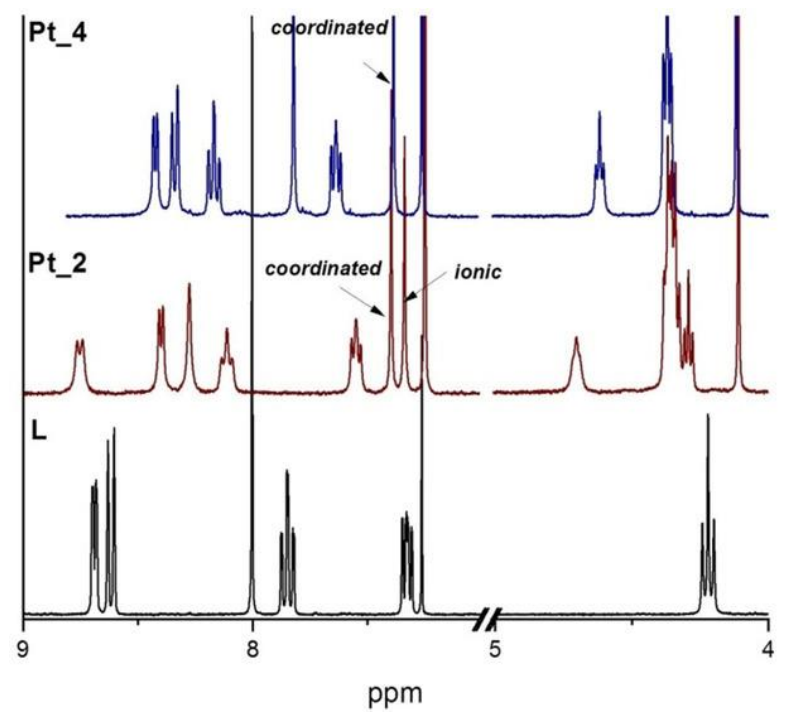

Figure $2{ }^{1} \mathrm{H}$ NMR spectra of ligand L, Pt_2 and Pt_4, showing the different chemical shifts of the aromatic proton belonging to the benzoate when they are coordinated or ionic.

\section{Thermal and mesomorphic behaviour (POM, TGA, DSC)}

The thermal behaviour was first investigated by POM, TGA and DSC. The complexes without the benzoate group (Pt_1, Pt_3 and Zn_1 in Scheme 1) were obtained as amorphous or crystalline solids with high melting points, and, as expected, deprived of liquid crystalline properties owing to the absence of aliphatic chains. The introduction of lipophilic gallate units as monodentate ligands (Pt_4 and Zn_2 in Scheme 1) or as both ligand and counter anion (Pt_2 in Scheme 1) resulted in the drastic lowering of the melting points for all and in the induction of mesomorphism for the former ones (Table 1).

The thermal behaviour of the platinum complex with two gallate groups, Pt_2, is rather peculiar and complicated, and requires some precision. During the first heating, a first broad, endothermic event is detected at around $37^{\circ} \mathrm{C}$ by DSC, and a texture characteristic of a hexagonal (Colnex) phase is easily recognised by POM (Figure $\underline{\mathbf{3}}$ and Figure SI-9 in the Supporting Information). On further heating, above $90^{\circ} \mathrm{C}$, phase co-existence is observed (between Col ${ }_{\text {hex }}$ phase and isotropic liquid), and the birefringence persists until the sample fully clears at $155^{\circ} \mathrm{C}$, at which temperature no more birefringence is seen. This very broad transition, spreading over several tens of degrees Celsius, was not detected by DSC. On cooling, the isotropic liquid and the Colnex phase were found to coexist again until a transition was detected at around $85^{\circ} \mathrm{C}$ by DSC, where two phases eventually co-exist. It is important to note that this transition was not seen by POM and that no textural change was evidenced either. On further cooling, the compound partly crystallises. This singular 
phenomenon is reversible on successive thermal cycles, and suggests the partial dissociation of one gallate group during the first thermal treatment, as later confirmed by S/WAXS. ${ }^{1} \mathrm{H}$ NMR and IR spectroscopy measurements performed on Pt_2 after one cycle of heating and cooling indeed confirmed the dissociation of the ionic gallate (see Figures SI-18 and SI-19 in the Supporting Information). This lack of thermal stability therefore precludes any conclusive remarks on its supramolecular behaviour.

Table 1. Thermal behaviour of $\mathrm{Pt}$ " and $\mathrm{Zn} "$ complexes.

\begin{tabular}{|c|c|c|}
\hline Complex & $\boldsymbol{T}_{\operatorname{dec} 5 \%\left[{ }^{\circ} \mathbf{C}\right]^{[\mathrm{a}]}}$ & $\begin{array}{l}\text { Thermal properties: mesophases, }{ }^{[\mathrm{b}]} \text { transition temperatures }{ }^{[\mathrm{c}]}\left[{ }^{\circ} \mathrm{C}\right] \text { and } \\
\text { enthalpies }\left(\Delta H\left[\mathrm{~kJ} \mathrm{~mol}^{-1}\right]\right)\end{array}$ \\
\hline Pt_1 & 155 & $\operatorname{Dec}^{[d]}$ \\
\hline $\mathbf{P t} \_2$ & 303 & 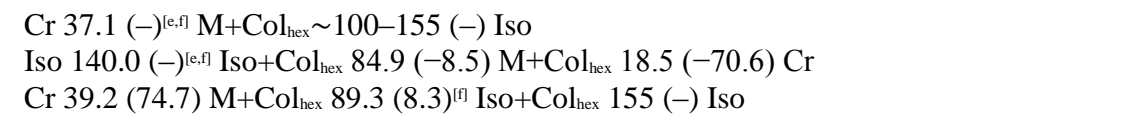 \\
\hline $\mathbf{P t} \_3$ & 280 & Cr $170(-)^{[e]}$ Iso \\
\hline Pt_4 & 285 & $\mathrm{LamCol}_{\mathrm{r}} 65-135(11.6)^{[\mathrm{fl}]} \mathrm{Lam}_{\mathrm{Col}} 255(-)^{[\mathrm{el}]}$ Iso \\
\hline Zn_1 & 246 & $\mathrm{Cr} 243(-)^{[e]}$ Iso \\
\hline $\mathrm{Zn} \_2$ & 309 & $\begin{array}{l}\mathrm{Col}_{\text {hex }} 101(2.2) \text { Iso } \\
\text { Iso } 108(-2.0) \text { Col hex }_{\text {hex }}\end{array}$ \\
\hline
\end{tabular}

- [a] Significant weight loss (5\%) from degradation from the TGA trace. [b] Determined on first cooling and second heating (for mesomorphous compounds), and only first heating for the other: $\mathrm{Cr}$, crystalline phase; Colnex, hexagonal columnar mesophase; Lam col, lamellar columnar mesophase; LamColr, lamellar columnar mesophase with rectangular symmetry; Iso, isotropic liquid. [c] Onset peaks. [d] Decomposition before melting. [e] POM observations. [f] Broad transition.
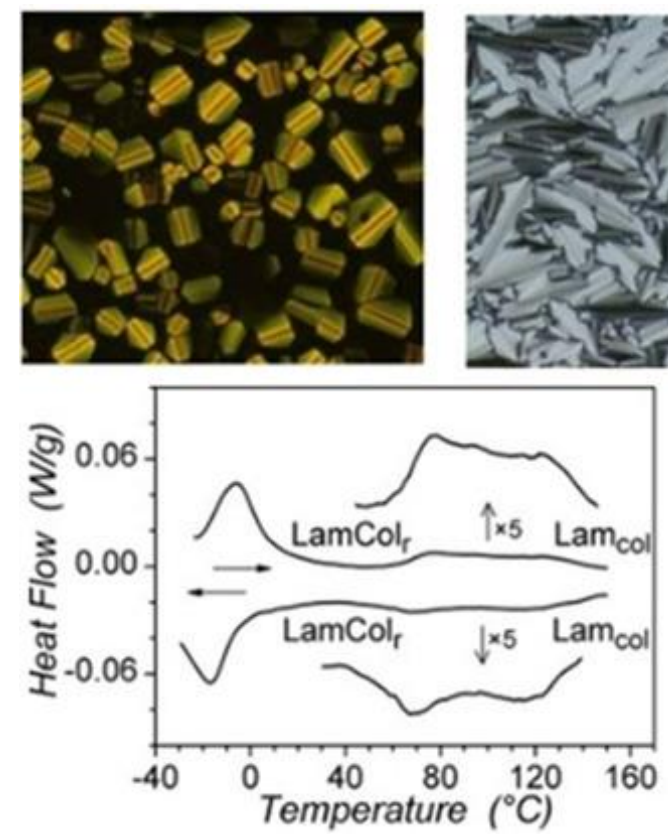
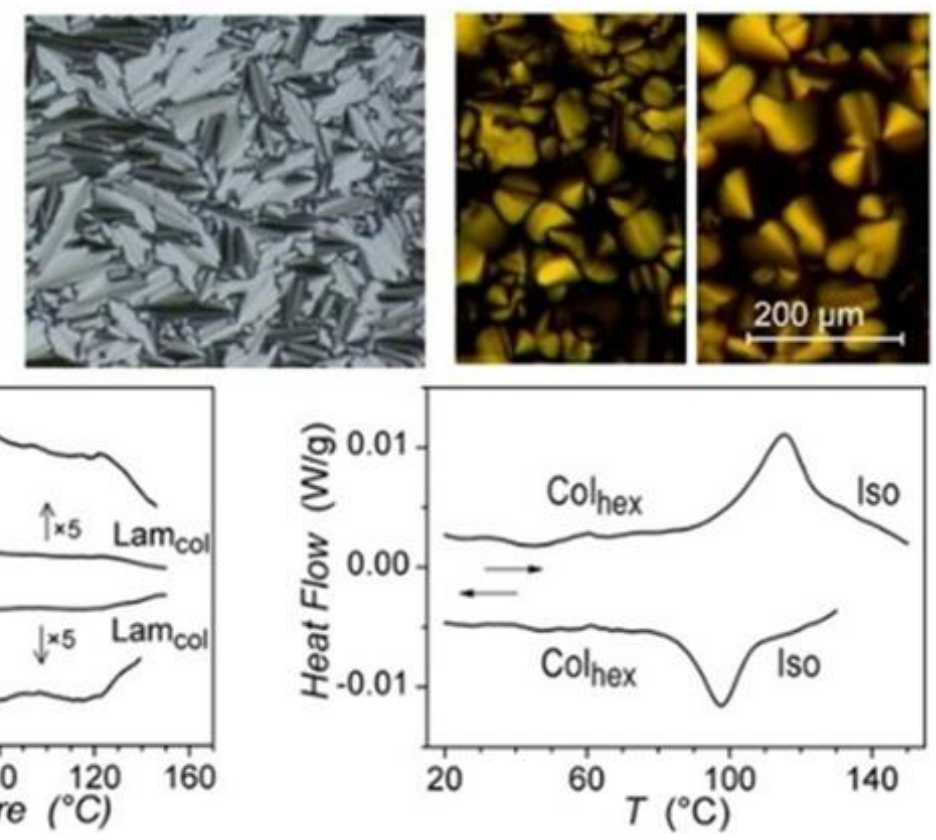
Figure 3 POM textures (top) of the Pt_2 sample at $35^{\circ} \mathrm{C}$ on first cooling, of Pt_4 at $175^{\circ} \mathrm{C}$ on second cooling, and of $\mathbf{Z n \_ 2}$ at 80 and $20^{\circ} \mathrm{C}$, respectively, on cooling. DSC traces (bottom) of Pt_4 and Zn_2.

The platinum complex with only one gallate group (Pt_4) is clearly mesomorphous from room temperature up to $255^{\circ} \mathrm{C}$, with a reversible phase transformation spreading over $70^{\circ} \mathrm{C}$, from approximately $65^{\circ} \mathrm{C}$ to $135^{\circ} \mathrm{C}$ between two mesomorphic states. Another broad transition to a likely crystalline state was detected below $0{ }^{\circ} \mathrm{C}$. Pt_ 4 exhibits a fan-shaped texture reminiscent of a lamellar arrangement (Figure $\underline{\mathbf{3}}$ and Figure $\mathrm{SI}-10$ in the Supporting Information). The Zn complex (Zn_2) is mesomorphous at room temperature up to a reversible but broad clearing transition at $101^{\circ} \mathrm{C}$. POM textures at $80^{\circ} \mathrm{C}$ in the mesophase and at room temperature, obtained on cooling from the isotropic state, display pseudo-focal-conic defects and homeotropic zones, which indicate the formation of an untilted Colnex mesophase (Figure $\underline{\mathbf{3}}$ and Figure SI-11 in the Supporting Information). In all cases, textures were preserved at room temperature.

\section{Characterisation of the mesophases by small- and wide-angle X-ray scattering (S/WAXS)}

Combined with S/WAXS investigation, lamello-columnar phases were eventually confirmed for Pt_4 from room temperature up to $255^{\circ} \mathrm{C}$, whereas a hexagonal mesophase was confirmed for Zn_2. The S/WAXS patterns, recorded for both samples at various temperatures, revealed several sharp and intense reflections in the small-angle range characteristic of the various twodimensional arrangements of mesogenic columns separated in space by a molten aliphatic continuum (Figure 4). For Zn_2, up to four reflections in the ratio $1: \sqrt{ } 3: 2: \sqrt{7}$ were observed, unambiguously characterising a hexagonal $p 6 \mathrm{~mm}$ lattice. The numerous sharp reflections of Pt_4 could be indexed according to a p2 $\mathrm{mg}$ rectangular lattice, with the arrangement of columns into a rectangular symmetry. In the large-angle region, a broad and diffuse scattering signal, emerging from undifferentiated lateral distances between the aliphatic chains and the gallate groups, respectively, $h_{\mathrm{ch}}+h_{\text {gal }}$, was systematically present and confirmed the fluid and liquid crystalline nature of all mesophases: these average lateral distances give rise to scattering maxima $h_{\text {gal }}$ and $h_{\mathrm{ch}}$, which are not resolved from the large scattering contribution $h_{\mathrm{ch}}$ from the molten chains in the periphery of the columns. An additional signal is observed for Pt_4, $h_{\pi}$, arising from the stacking distances between successive tpy-platinum complexes into columns: this signal is rather sharp, suggesting a regular stacking of the complex along the columns. This signal is not present for the zinc complex, indicating that the stacking is completely undifferentiated from the broad scattering, $h_{\mathrm{ch}}+h_{\mathrm{gal}}$. For this latter complex, another scattering maximum with a two-core periodicity $\left(h_{\mathrm{ch}}+h_{\mathrm{gal}}+h_{\mathrm{\pi}}\right) / 2$ was distinguished, in relation to the change of in-plane orientation 
between successive cores. The S/WAXS patterns recorded at various temperatures for complex Pt_2 unfortunately confirmed the erratic behaviour owing to the dissociation of the ionic gallate and the co-existence of two or more species, making the phase identification impossible (Figure SI-13 in the Supporting Information).
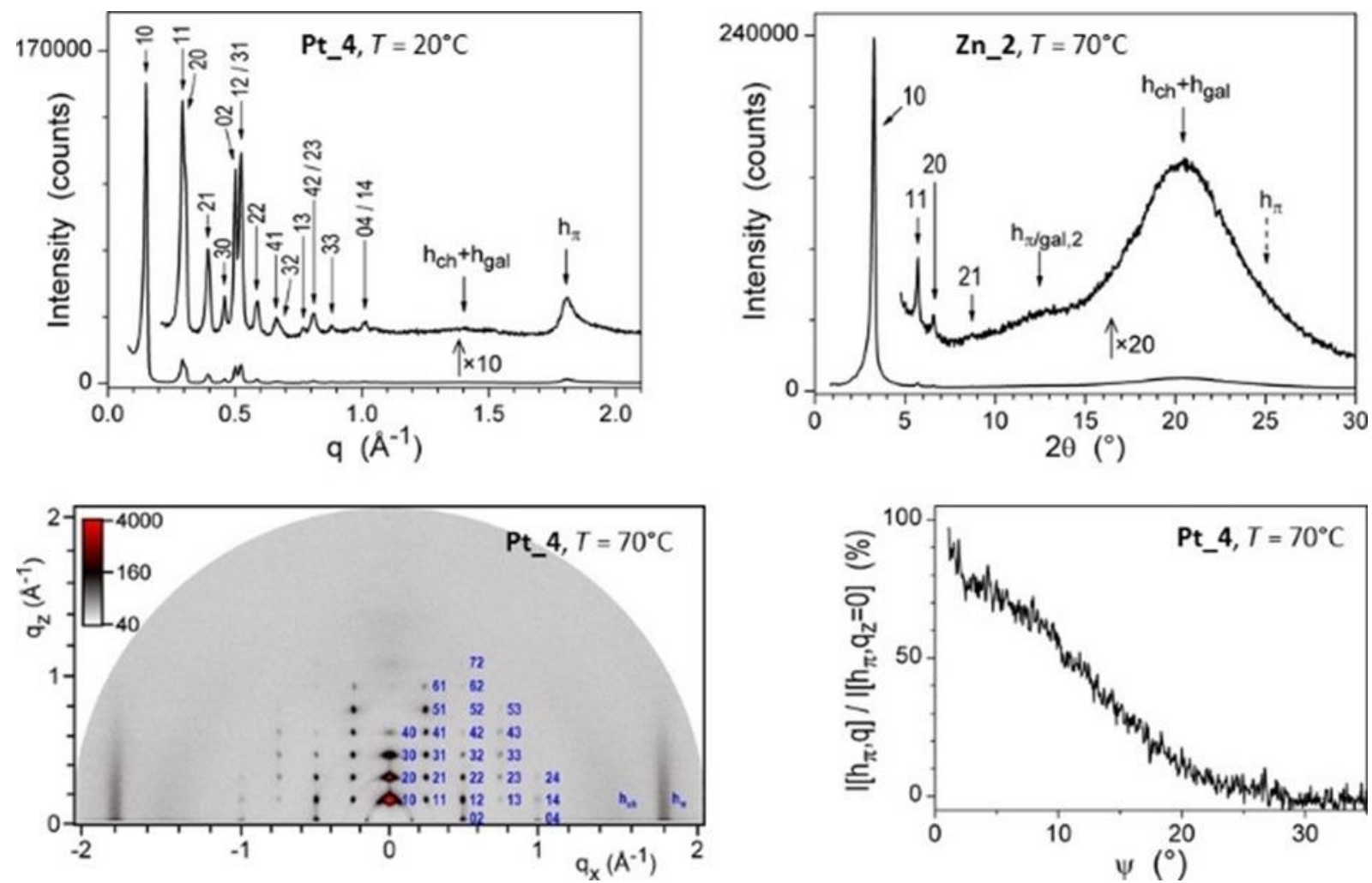

Figure 4 Representative SNAXS (top) and GIWAXS (bottom) patterns of Pt_4 (in the lowtemperature LamColrphase) and Zn_2 (in the Colnex). In the thin-film pattern, the $b$-axis and $h_{\pi}$ scattering lie in the equatorial plane and lamellae are thus parallel to the substrate (see text). The profile analysis of the strip-like $h_{\pi}$ scattering further reveals that complexes fluctuate out of the lamellar plane by roughly $10^{\circ}$.

The columns of the Colnex phase of $\mathbf{Z n \_ 2}$ are constituted by a core of piled complexes and a crown of irregularly closed-packed gallate units, the average lateral distances of which give rise to scattering maximums $h_{\text {gal }}$ and $h_{\mathrm{ch}}$, which are not resolved from the scattering contribution $h_{\mathrm{ch}}$ from the molten chains in the periphery of columns. The distribution of gallate units and chains around piled complexes results in the appearance of a scattering maximum from a two-cores periodicity $h_{\pi / g a l, 2}$, in relation to the change of in-plane orientation of successive cores. For this compound, it turns out that the number of chains and the size of the cores are well adapted, so that molecules self-assemble in an untilted Colnex phase, with $h_{\text {mol }}$ close to the natural stacking distance of tpy-zinc(II) (Figure SI-16 in the Supporting Information) and with a chain packing ratio, ${ }^{[47]} q_{\mathrm{ch}}$, slightly above unity (Table 2). The stacking distance of the tpy rings is indeed $3.2945 \AA$ at $25^{\circ} \mathrm{C}$ in the single-crystal structure CSD-TPYZNC ${ }^{[48]}$ of the dichloro-terpyridyl-zinc(II) complex, thus is nearly the same as in the frozen Colhex state of $\mathbf{Z n \_ 2}$. The $q_{\mathrm{ch}}$ value around 1.1 corresponds to 
almost stretched chains, favouring the formation of sharp nanosegregation interfaces with piled cores and thus columnar mesomorphism.

Table 2. Mesophase parameters of complex Zn_2.

\begin{tabular}{|c|c|c|c|c|c|c|c|}
\hline $\begin{array}{l}\text { Phase } \\
T^{[\mathrm{a}]}\end{array}$ & $\underset{\text { b] }}{V_{\text {mol }}} \rho^{[}$ & $\begin{array}{l}a \\
A[Z]^{[\mathrm{c}]}\end{array}$ & $h_{\mathrm{mol}^{[\mathrm{d}]}}$ & $\begin{array}{l}\chi_{\text {Vch }} \\
A_{\text {core }}{ }^{[\mathrm{e}]}\end{array}$ & $D_{\text {cyl }^{[f]}}$ & $S_{\text {ch,cyl }}{ }^{[g]}$ & $q_{\text {ch,cyl }^{[h]}}$ \\
\hline $\begin{array}{l}\mathrm{Col}_{\text {hex }} \\
70\end{array}$ & $\begin{array}{l}3025 \\
1.04\end{array}$ & $\begin{array}{l}31.32 \\
850[1]\end{array}$ & 3.56 & $\begin{array}{l}0.778 \\
189\end{array}$ & 15.5 & 24.8 & 1.12 \\
\hline $\begin{array}{l}\mathrm{Col}_{\text {hex }} \\
30\end{array}$ & $\begin{array}{l}2946 \\
1.07\end{array}$ & $\begin{array}{l}32.08 \\
891[1]\end{array}$ & 3.31 & $\begin{array}{l}0.775 \\
200\end{array}$ & 16.0 & 23.7 & 1.11 \\
\hline
\end{tabular}

- [a] $T$, temperature of the measurement $\left({ }^{\circ} \mathrm{C}\right)$. [b] $V_{\text {mol, }}$ calculated molecular volume $\left(\AA^{3}\right) ; \rho$, density $\left(\mathrm{g} \mathrm{cm}^{-3}\right)$. [c] a, lattice parameter $(\AA) ; A=a^{2} \sqrt{3} / 2$, lattice area $\left(\AA^{2}\right) ; Z$, number of columns per lattice. [d] $h_{\mathrm{mol}}=V_{\mathrm{mol}} / A$, molecular slice thickness (A). [e] $X_{\mathrm{vch}}$, calculated aliphatic volume fraction; $A_{\text {core }}=\left(1-X_{\text {von }}\right) \times(A / Z)$, cross-sectional area of columnar cores $\left(\AA^{2}\right)$. [f] $D_{\text {cyl }}=\sqrt{ }\left(4 / \pi A_{\text {core }}\right)$, diameter $(\AA)$ of equivalent cylinder of cross-sectional area $A_{\text {core. }}$ [g] $S_{\text {ch, cyl }}=\pi D_{\text {cy }} \times h_{\text {mo }} / n_{\text {ch }}$ : cylinder area per chain $\left(\AA^{2}\right), n_{\mathrm{ch}}=7$, the number of chains per molecule. [h] $q_{\mathrm{ch}}=S_{\mathrm{ch}, \mathrm{cos}} / \sigma_{\mathrm{ch}}$, chain packing ratio, $\sigma_{\mathrm{ch}}=21.2\left(\AA^{2}\right)$, the cross-sectional area of a molten chain at $20^{\circ} \mathrm{C}$.

For the LamColr, the glide line coincides with the $b$-axis, along which column rows and counter ions compactly self-assemble into layers (Figure $\underline{\mathbf{5}}$ ). The sequence of column layers and of intermediate molten chain layers along the a-axis generates a lamellar periodicity, $d_{\text {lam, }}$ giving a very strong firstorder reflection $(10)$ and reflections series $(h I)$ that extend to high $h$. In the thin-film pattern, the $b$ axis and $h_{\pi}$ scattering lie in the equatorial plane and lamellae are thus parallel to the substrate. The profile analysis of the strip-like $h_{\pi}$ scattering further reveals that complexes fluctuate out of the lamellar plane by roughly $10^{\circ}$ (Figure $\underline{4}$, bottom right).
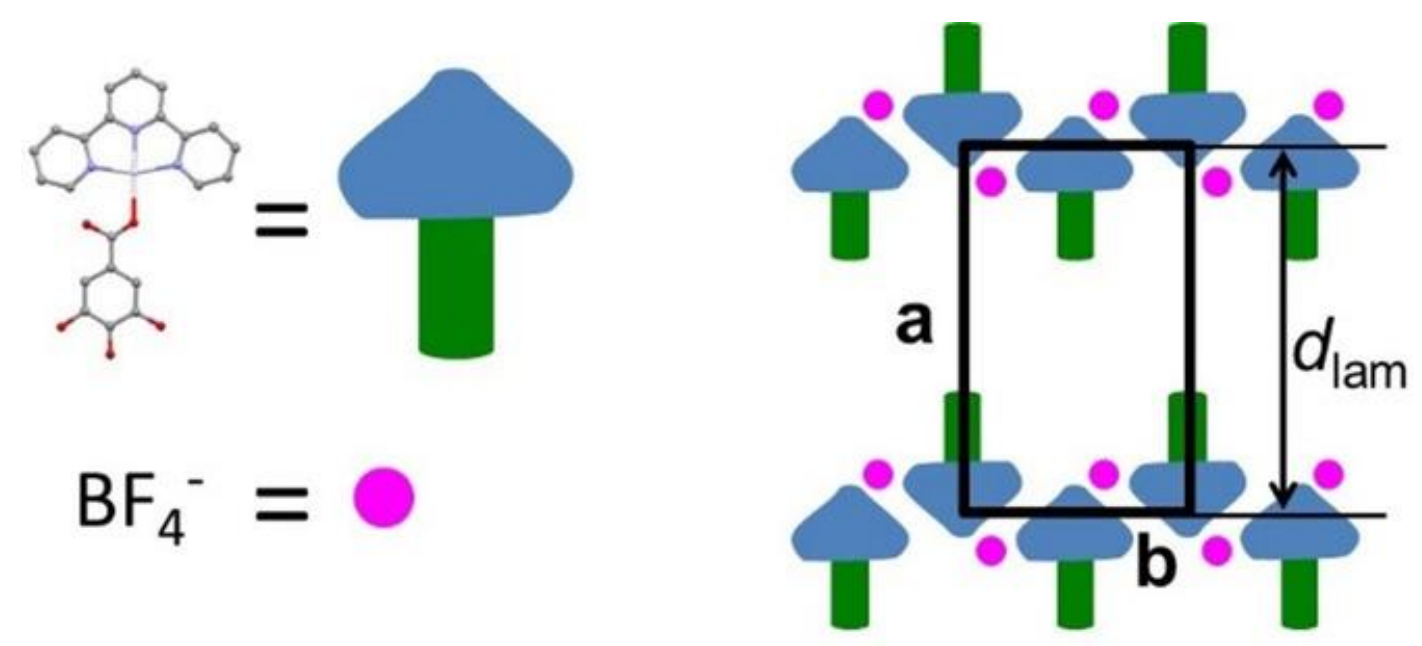

Figure 5 Left: model of terpyridyl-platinum complex moieties and gallate units, as reconstructed from single-crystal structures CSD-RAXFIH ${ }^{[49]}$ and CSD-IJUMEG. ${ }^{[50]}$ Right: schematic 
representation of the likely molecular organization in the LamColr mesophase of $p 2 m g$ symmetry. Columns of stacked complexes and $\mathrm{BF}_{4}{ }^{-}$counter ions arrange in staggered rows; gallate units and molten alkyl chains (not represented) fill the gaps between successive staggered rows. The $a$-axis coincides with a lamellar periodicity $d_{\mathrm{lam}}$, maintained after heating in the Lamcol mesophase, whereas the rectangular long-range lattice is suppressed by thermal fluctuations allowing successive column rows to move laterally one to another.

Terpyridyl-platinum complexes stack into columns that self-assemble with counter ions into layers alternating with aliphatic chains. At low temperature, the rings are nearly orthogonal to layers ( $\left.h_{\mathrm{mol}} \approx h_{\mathrm{T}}\right)$, and the chains stretch onto the layer normal $\left(q_{\mathrm{ch}} \approx 1\right)$; the superimposition of layers defines a rectangular lattice of one-lamella and two-column periodicity (Table $\underline{\mathbf{3}}$ ). At higher temperature, fluctuations of ring orientations out of the lamellar plane are enhanced $(\langle\psi\rangle\rangle\rangle)$, which causes elongation of columns $\left(h_{\mathrm{mol}}>h_{\pi}\right)$ and lateral expansion of lamellae (higher $A_{\mathrm{mol}}$ and $q_{\mathrm{ch}}$ ), which in turn affects the regularity of $\pi$-stacking (lower $\xi$ ). The columnar superstructure finally vanishes in the following lamello-columnar mesophase (Lam ${ }_{\mathrm{Col}}$ ), which preserves the long-range correlated lamellar structure and a local-range ribbon periodicity from average lateral distances between piled complexes $(D)$.

Table 3. Mesophase parameters of complex Pt_4.

\begin{tabular}{|c|c|c|c|c|c|c|c|}
\hline $\begin{array}{l}\text { Phase } \\
T_{\text {[a] }}\end{array}$ & $\begin{array}{l}V_{\text {mol }} \\
\rho^{[b]}\end{array}$ & $\begin{array}{l}a \\
b \\
A[Z] \\
d_{\text {lam }}\left[N_{\mathrm{L}}\right]^{[\mathrm{c}]} \\
D[\xi]^{[\mathrm{d}]}\end{array}$ & $\begin{array}{c}A_{\text {mol }} \\
S_{\text {ch }} \text { [e] }\end{array}$ & $\boldsymbol{q}_{\mathrm{ch}}^{[\mathrm{ff}]}$ & $\begin{array}{l}D_{\text {col }} \\
S_{\text {col }}[\mathrm{g}]\end{array}$ & $\begin{array}{l}\boldsymbol{h}_{\text {mol }} \\
\boldsymbol{h}_{\pi} \\
{[\xi]^{[\mathrm{h}]}}\end{array}$ & $\psi^{[\mathrm{i}]}$ \\
\hline $\begin{array}{l}\mathrm{LamCol}_{r} \\
20\end{array}$ & $\begin{array}{l}1820 \\
1.28\end{array}$ & $\begin{array}{l}41.20 \\
25.11 \\
1035[2] \\
41.20[1] \\
-\end{array}$ & $\begin{array}{l}44.2 \\
22.1\end{array}$ & 1.04 & $\begin{array}{l}12.55 \\
517\end{array}$ & $\begin{array}{l}3.52 \\
3.48 \\
{[90]}\end{array}$ & 9 \\
\hline $\begin{array}{l}\mathrm{LamCol}_{r} \\
70\end{array}$ & $\begin{array}{l}1880 \\
1.24\end{array}$ & $\begin{array}{l}40.60 \\
25.16 \\
1022[2] \\
41.60[1] \\
-\end{array}$ & $\begin{array}{l}46.3 \\
23.1\end{array}$ & 1.05 & $\begin{array}{l}12.58 \\
511\end{array}$ & $\begin{array}{l}3.68 \\
3.51 \\
{[70]}\end{array}$ & 17 \\
\hline $\begin{array}{l}\operatorname{Lam}_{\text {Col }} \\
140\end{array}$ & $\begin{array}{l}1960 \\
1.19\end{array}$ & $\begin{array}{l}- \\
36.90[1] \\
12.5[60]\end{array}$ & $\begin{array}{l}53.2 \\
26.6\end{array}$ & 1.15 & $\begin{array}{l}12.5 \\
462\end{array}$ & $\begin{array}{l}4.24 \\
3.54 \\
{[40]}\end{array}$ & 33 \\
\hline $\begin{array}{l}\operatorname{Lam}_{\mathrm{Col}} \\
180\end{array}$ & $\begin{array}{l}2010 \\
1.16\end{array}$ & $\begin{array}{l}- \\
35.17[1] \\
12.2[60]\end{array}$ & $\begin{array}{l}57.1 \\
28.6\end{array}$ & 1.20 & $\begin{array}{l}12.2 \\
429\end{array}$ & $\begin{array}{l}4.68 \\
3.56 \\
{[25]}\end{array}$ & 40 \\
\hline
\end{tabular}


- [a] Temperature of the measurement $\left({ }^{\circ} \mathrm{C}\right)$. [b] $V_{\text {mol }}$, calculated molecular volume $\left(\AA^{3}\right) ; \rho$, density $\left(\mathrm{g} \mathrm{cm}^{-3}\right)$. [c] $a, b, A=a \times b$, Z: lattice parameters $(\AA)$, lattice area $\left(\AA^{2}\right)$ and number of columns per lattice; $d_{\mathrm{lam}}, N_{\llcorner}$: lamellar periodicity $(\AA)$ and number of molecular layers per lamella (LamCol $\left.: d_{\mathrm{lam}}=a\right)$ (for LamCol, only). [d] $D, \xi$ : average distance between columns from scattering maximum $(\AA)$ and associated correlation length $(\AA$, Scherrer equation with $K=0.9)$ (for $\mathrm{Lam}_{\mathrm{col}}$ only). [e] $A_{\mathrm{mol}}=V_{\text {mol }} /\left(d_{\text {lam }} / N_{\mathrm{L}}\right)$ molecular area $\left(\AA^{2}\right) ; S_{\mathrm{ch}}=A_{\mathrm{mol}} / 2$ : area per chain in the lamellar plane $\left(\AA^{2}\right)$. [f] $q_{\mathrm{ch}}=S_{\mathrm{ch}} / \sigma_{\mathrm{ch}}$, chain packing ratio, $\sigma_{\mathrm{ch}}=21.2 \AA^{2}$ at $T=20^{\circ} \mathrm{C}$, being the cross-sectional area of a molten chain. [g] $D_{\mathrm{col}}$ : distance between columns in the lamellar plane $(\AA)\left(\right.$ LamColr: $\left._{\text {col }}=b / 2 ; \operatorname{Lam}_{\mathrm{col}}: D_{\mathrm{col}}=D\right) ; S_{\mathrm{col}}=D_{\mathrm{col}} \times\left(d_{\mathrm{lam}} / N_{\mathrm{L}}\right)$ : crosssectional area of a column $\left(\AA^{2}\right)$. [h] $h_{\text {mol }}=V_{\text {mol }} / S_{\text {col }}$ : molecular slice thickness $(\AA) ; h_{\pi}, \xi$ : distance between stacked complexes from scattering maximum $(\AA)$ and associated correlation length $(\AA$, Scherrer equation with $K=0.9)$. [i] $\psi=\operatorname{acos}\left(h_{\pi} / h_{\text {mol }}\right)$ : mean out of plane tilt angle of stacked complexes $\left({ }^{\circ}\right)$.

\section{Photophysical characterisation}

The photophysical properties of the complexes have been investigated in DMSO solution for Pt_1, Pt_3, Pt_4, in $\mathrm{CH}_{2} \mathrm{Cl}_{2}$ solution for Pt_2, Zn_1, Zn_2 and in the solid state for all samples. The results are summarised in Table $\underline{\mathbf{4}}$ and Table $\underline{\mathbf{5}}$.

Table 4. Photophysical properties of the complexes in solution at room temperature.

\begin{tabular}{|c|c|c|c|c|}
\hline Sample & Absorption, $\lambda_{\max }[\mathrm{nm}]\left(\epsilon\left[\mathrm{M}^{-1} \mathrm{~cm}^{-1}\right]\right)$ & $\begin{array}{l}\text { Emission } \\
\lambda_{\max }[\mathrm{nm}]\end{array}$ & $\begin{array}{l}\text { Quantum } \\
\text { yield, } \Phi[\%]\end{array}$ & $\begin{array}{l}\text { Lifetime } \\
\tau[\mathrm{ns}]\end{array}$ \\
\hline $\mathbf{P t} \mathbf{1}^{[\mathrm{a}]}$ & $\begin{array}{l}286(24780), 305(13330), 320(13940), 334 \\
(15580), 372(3930), 395(3960), 459(650)\end{array}$ & 620 & 0.8 & 380 \\
\hline $\mathbf{P t} 2^{[\mathrm{b}]}$ & $\begin{array}{l}285(6310), 306(2700), 317(2370), 332(1990), 381 \\
(660), 393(630), 459(60)\end{array}$ & 600 & 1.7 & 397 \\
\hline $\mathbf{P t} \_\mathbf{3}^{[\mathrm{cc}]}$ & $\begin{array}{l}286(78320), 305(41990), 320(41770), 334 \\
(46580), 368(10690), 396(11670), 455(1950)\end{array}$ & 615 & 0.5 & 338 \\
\hline $\mathbf{P t} \_\mathbf{4}^{[\mathrm{d}]}$ & $\begin{array}{l}285(25630), 302(14650), 317(13370), 333 \\
(12570), 367(4030), 395(3400), 469(800)\end{array}$ & 650 & 0.2 & 251 \\
\hline $\mathbf{Z n} \_1^{[\mathrm{e}]}$ & $248,275,311,323$ & 365 & 6.4 & 1.2 \\
\hline Zn_2 ${ }^{[\mathrm{f}]}$ & $\begin{array}{l}258(28030), 285 \quad(15150), 306 \quad(11620), 319 \\
(10100)\end{array}$ & 379 & 24.5 & 2.7 \\
\hline
\end{tabular}

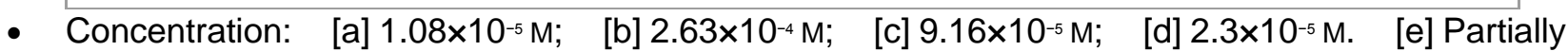
soluble, $\epsilon$ data not available. [f] $3.96 \times 10^{-6} \mathrm{M}$.

Table 5. Photophysical properties of the complexes in the condensed state at room temperature.

\begin{tabular}{|llll|}
\hline Sample & $\begin{array}{c}\text { Emission } \\
\lambda_{\max }[\mathbf{n m}]\end{array}$ & $\begin{array}{l}\text { Quantum yield } \\
\boldsymbol{\Phi}[\%]\end{array}$ & $\begin{array}{l}\text { Lifetime } \\
\boldsymbol{\tau}[\mathbf{m s}]\left[\boldsymbol{\alpha}_{\mathbf{i}}(\boldsymbol{\%})\right]\end{array}$ \\
\hline Pt_1 & 676 & 19.9 & 412 \\
Pt_2 & 650 & 1.1 & 475 \\
Pt_3 & 690 & 14.0 & 272 \\
Pt_4 & 660 & 1.8 & 300 \\
\hline
\end{tabular}




\begin{tabular}{|llll|}
\hline Sample & $\begin{array}{c}\text { Emission } \\
\lambda_{\max }[\mathbf{n m}]\end{array}$ & $\begin{array}{l}\text { Quantum yield } \\
\boldsymbol{\Phi}[\boldsymbol{\%}]\end{array}$ & $\begin{array}{l}\text { Lifetime } \\
\boldsymbol{\tau}[\mathbf{n s}]\left[\boldsymbol{\alpha}_{\mathbf{i}}(\boldsymbol{\%})\right]\end{array}$ \\
\hline $\mathbf{Z n \_ 1}$ & 360 & 15.8 & 78.5 \\
$\mathbf{Z n \_ 2}$ & 450 & 7.1 & $0.4[23], 3[69], 11[8]$ \\
\hline
\end{tabular}

All Pt" complexes present a pale-yellow colour in diluted solutions and absorb in the UV region with weak bands in the visible region of the electromagnetic spectra (Figure $\underline{\mathbf{6}} \mathrm{a}$ ). The spectra show a well-resolved structure with numerous peaks, which can be grouped in three main regions: lowest intensity bands in the $450-500 \mathrm{~nm}$ range; medium-intensity peaks in the $370-400 \mathrm{~nm}$ region; highintensity bands below $350 \mathrm{~nm}$. Although the spectral shape is almost unvaried on changing the counter ion or the ancillary ligand, the $\epsilon$ values are different.
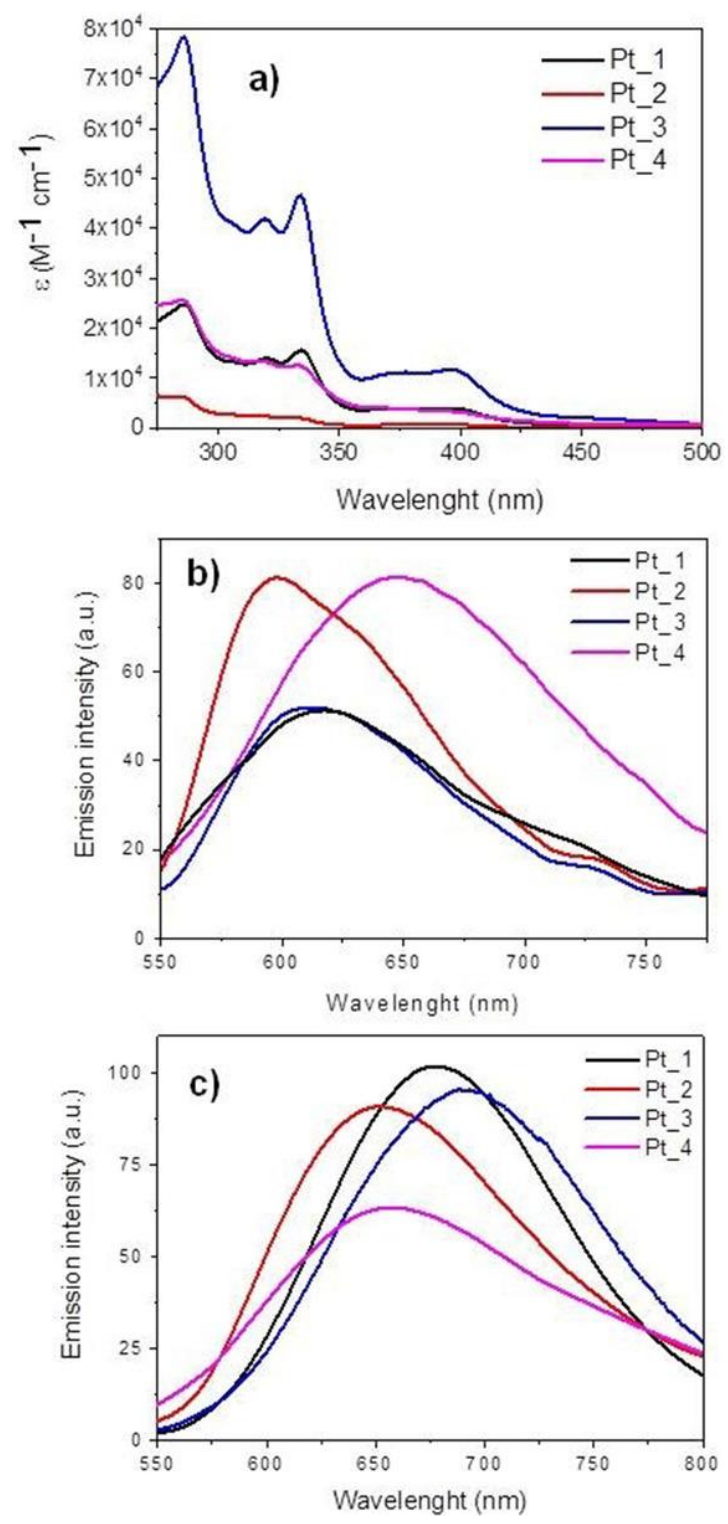
Figure 6 (a) Absorption spectra of Pt" complexes in DMSO (Pt_1, Pt_3, Pt_4) or $\mathrm{CH}_{2} \mathrm{Cl}_{2}$ (Pt_2) solutions. (b) Emission spectra of Pt" complexes in DMSO (Pt_1, Pt_3, Pt_4) or $\mathrm{CH}_{2} \mathrm{Cl}_{2}$ (Pt_2) solutions at room temperature. Concentrations are reported in Table $\underline{4}$. (c) Emission spectra of $\mathrm{Pt}$ "l complexes in condensed phase at room temperature.

All solutions are weakly fluorescent at room temperature (Figure $\underline{6} b$ ), with broad and structureless emission bands in the green-red region (peaks located from 600 to $650 \mathrm{~nm}$ ) of the visible spectrum. The emission quantum yields measured in air-equilibrated solution at room temperature are low and range from 0.2 to $1.7 \%$. The emission intensity decay has been fitted with a mono-exponential function giving lifetime values between 251 and 397 ns (Table $\underline{4}$ ).

Platinum tpy complexes are well known to form aggregates through metal $\cdots$ metal $/ \pi \cdots \pi$ interactions, ${ }^{[51-54]}$ which give rise to various excited states. The combined effect of the counter ion nature, the solution concentration and the solvent polarity modulates the photophysical properties of these complexes. On this basis, the $459 \mathrm{~nm}$ (Pt_1) and $455 \mathrm{~nm}$ (Pt_3) absorption bands in the first spectral region above identified, are attributed to a metal-metal-to-ligand charge transfer (MMLCT) excited state, indicative of Pt-Pt dimerization in Pt_1 and Pt_3, both bearing the chlorine ancillary ligand. When this ligand is replaced by a benzoate, as in the case of Pt_2 and Pt_4, the bands at 459 and $469 \mathrm{~nm}$, respectively, are attributed to a $\pi-\pi^{*}$ transition of the tpy-tpy bound dimer, the Pt-Pt interaction being hampered by the steric hindrance of the gallate ligand. The absorption bands in the second spectral region (superimposable in the DMSO-dissolved complexes, and slightly redshifted in the $\mathrm{CH}_{2} \mathrm{Cl}_{2}$-dissolved compounds) are due to a metal-to-ligand charge transfer $\left(\mathrm{d}-\pi^{*} \mathrm{MLCT}\right)$ transition from $\mathrm{Pt}$ "to the tpy ligand. Finally, the bands in the third region are attributed to a ligand-centred $\left(\pi-\Pi^{*} L C\right)$ transition on the tpy ligand. Pt_1 and Pt_3 show an emission band at 620 and $615 \mathrm{~nm}$, respectively, owing to the ${ }^{3 M M L C T}$ deactivation. The Pt_2 and Pt_4 broad, unstructured emission band (peaked at 600 and $650 \mathrm{~nm}$, respectively) is ascribed to an excimeric emission, which accounts for the large Stokes shift observed for Pt_4 compared with Pt_1 and Pt_3; the blueshift observed for Pt_2 emission is ascribed to the different solvent in which the compound has been dissolved. This different aspect of the emission spectra of the complexes bearing a chlorine as an ancillary ligand (Pt_1 and Pt_3) compared with those that bind a gallate (Pt_2 and Pt_4), confirms the different attribution of the lowest excited state, that is, an MMLCT in the case of the first pair, and an excimer (formed by means of $\pi-\pi$ interactions between the aromatic rings of tpy) in the case of the second pair.

In the Supporting Information (Figure SI-21), the absorption spectra of platinum complexes at different concentrations are reported. It can be seen that as the concentration increases, the ratio between the bands attributed to the intermolecular interactions and those attributed to transitions on the single molecule, tends to grow, which is evidence for aggregation in solution. 
Emission spectra recorded from solid samples at room temperature (Figure $\underline{\mathbf{6}} \mathrm{c}$ ) have the same structure as those collected in solution under the same conditions. All show a redshift with respect to the solutions, but more accentuated for the complexes that bind chlorine (Pt_1 and Pt_3, which emit with a maximum at 676 and $690 \mathrm{~nm}$, respectively) than for those that bind benzoate (Pt_2 and Pt_4, which emit with a maximum at 650 and $660 \mathrm{~nm}$, respectively). Emission quantum yields and lifetimes in the condensed phase undergo a significant variation with respect to the values recorded in solution for Pt_2 and Pt_4, but this variation is much more consistent for Pt_1 and Pt_3 (see Table $\underline{4}$ and Table $\underline{\mathbf{5}}$ ). In fact, the complexes bearing chlorine in solid samples show a redshifted emission maximum and an enhancement of the luminescence intensity with respect to the solution, whereas for the complexes with benzoate ligand these differences are smaller. This behaviour reflects the different origin of the emitting state for the two classes of compounds: for Pt_1 and Pt_3, the small steric hindrance of chlorine reinforces the Pt-Pt interaction in the solid, giving rise to an MMLCT excited state. On the contrary, the bulky benzoate group in Pt_2 and Pt_4 does not allow a Pt-Pt interaction, whereas weak $\pi-\pi$ interactions on the tpy ligands give rise to the formation of excimers, similarly to the solution.

The photophysical behaviour of Pt_2 and Pt_4 was explored by changing the temperature. Both samples continue to emit during the heating and cooling cycles between 30 and $160^{\circ} \mathrm{C}$, retaining their emission maxima exhibited in the solid sample, that is, $650 \mathrm{~nm}$ and $660 \mathrm{~nm}$ for Pt_2 and Pt_4, respectively. The emission quantum yields have been measured at various temperatures (Table $\underline{\mathbf{6}}$ and Table $\mathbf{7}$ ). For Pt_2, two heating/cooling cycles have been recorded, interspersed with cooling in the freezer (at $-20^{\circ} \mathrm{C}$ ) for $30 \mathrm{~min}$. For Pt_4, three cycles have been performed; between the end of the second cycle and the start of third cycle, the sample was cooled in the fridge (at $4{ }^{\circ} \mathrm{C}$ ) for 2 h.

Table 6. Quantum yields for Pt_2 by varying the temperature; emission maximum $\lambda_{\max }=650 \mathrm{~nm}$.

\begin{tabular}{|c|c|c|c|c|c|c|c|}
\hline First cy. & & & & Second c & & & \\
\hline Heatin & & Coolin & & Heating & & & Cooling \\
\hline $\boldsymbol{T}\left[{ }^{\circ} \mathbf{C}\right]$ & $\Phi[\%]$ & $\boldsymbol{T}\left[{ }^{\circ} \mathbf{C}\right]$ & $\Phi[\%]$ & $\boldsymbol{T}\left[{ }^{\circ} \mathbf{C}\right]$ & $\Phi[\%]$ & $\boldsymbol{T}\left[{ }^{\circ} \mathbf{C}\right]$ & $\Phi[\%]$ \\
\hline 30 & 1.10 & 120 & 0.05 & 30 & 1.42 & 120 & 0.12 \\
\hline 50 & 2.00 & 90 & 0.09 & 50 & 1.02 & 90 & 0.16 \\
\hline 90 & 1.24 & 50 & 0.33 & 90 & 0.18 & 50 & 0.59 \\
\hline 120 & 0.21 & 30 & 0.75 & 120 & 0.12 & 30 & 1.05 \\
\hline 160 & 0.03 & & & 160 & 0.01 & & \\
\hline
\end{tabular}


Generally, the quantum yield decreases as the temperature increases, owing to thermal agitation, which favours the non-radiative deactivation pathway. For Pt_4, the experimental data follow this trend, after an initial steeper decrease on first heating, related to the development of the LamCol ${ }_{r}$ structure with the softening of the sample. Values on cooling and second heating stabilise around $0.5 \%$ in this phase and decrease to $0.2 \%$ in the less-ordered Lamcol phase, prior to dropping to below $0.1 \%$ in the isotropic liquid state. This rational dependence upon structure contrasts with findings for the Pt_2 sample, which shows an increase in the quantum yield during the first cycle, whereas from the beginning of the second cycle, the emission quantum yield is higher than the value measured in the solid. This peculiar behaviour can be rationalised by considering that on heating Pt_2 during the first cycle eliminates one gallate unit and the metal centres are getting closer, which explains the increase of luminescence by Pt-Pt interactions.

Table 7. Quantum yields for Pt_4 by varying the temperature; emission maximum $\lambda_{\max }=660 \mathrm{~nm}$.

\begin{tabular}{|llllllll|}
\multicolumn{7}{l}{ First cycle } & \multicolumn{7}{c|}{ Second cycle } \\
Heating & \multicolumn{3}{c}{ Cooling } & Heating & Cooling \\
$\boldsymbol{T}\left[{ }^{\circ} \mathbf{C}\right]$ & $\boldsymbol{\Phi}[\%]$ & $\boldsymbol{T}\left[{ }^{\circ} \mathbf{C}\right]$ & $\boldsymbol{\Phi}[\%]$ & $\boldsymbol{T}\left[{ }^{\circ} \mathbf{C}\right]$ & $\boldsymbol{\Phi}[\%]$ & $\boldsymbol{T}\left[{ }^{\circ} \mathbf{C}\right]$ & $\boldsymbol{\Phi}[\%]$ \\
30 & 1.80 & 150 & 0.07 & 30 & 0.56 & 150 & 0.11 \\
50 & 1.29 & 100 & 0.17 & 50 & 0.45 & 100 & 0.19 \\
100 & 0.50 & 50 & 0.41 & 100 & 0.22 & 50 & 0.41 \\
150 & 0.08 & 30 & 0.56 & 150 & 0.11 & 30 & 0.57 \\
160 & 0.06 & & & 160 & 0.08 & & \\
\hline
\end{tabular}

The absorption spectra of $\mathbf{Z n \_ 1}$ and $\mathbf{Z n \_ 2 ~ c o m p l e x e s ~ r e c o r d e d ~ i n ~} \mathrm{CH}_{2} \mathrm{Cl}_{2}$ solution (Figure $\mathbf{7}$ a) show a series of bands (Table $\underline{4}$ ) in the UV portion of the electromagnetic spectrum, all originating from tpy LC transitions. ${ }^{[55-56]}$

In particular, for Zn_2, these transitions overlap with those localised on the benzoate ligand, giving rise to a broad band below $300 \mathrm{~nm}$. Interestingly, by comparing the absorption spectra of the zinc complexes with that of the tpy ligand (see Figure SI-20 in the Supporting Information), it can be noted that in this last one the bands above $300 \mathrm{~nm}$ are very low in intensity, whereas in the absorption spectra of the complexes, these bands have an intensity comparable with those of the other bands. This different spectral behaviour is due to the different symmetry of the free and zincbonded terpyridine; the free tpy shows the nitrogen atoms of the lateral pyridines both facing the opposite side with respect to the nitrogen atom of the central pyridine, ${ }^{[56]}$ whereas when the tpy binds a zinc ion all the nitrogen atoms are facing the same side. Both complexes are fluorescent, 
showing an asymmetric emission band at $365 \mathrm{~nm}$ (with a vibronic shoulder at $\mathbf{3 8 6} \mathrm{nm}$ ) for Zn_1, and at $379 \mathrm{~nm}$ (and a long tail extending towards the green spectral range) for $\mathbf{Z n \_ 2 ~ ( F i g u r e ~} \mathbf{Z}$ a). The luminescence intensity is quite high, with an emission quantum yield of $6.4 \%$ for $\mathbf{Z n} \_1$ and $24.5 \%$ for Zn_2; time-resolved measurements give a mono-exponential decay of the excited states, with lifetimes of, respectively, 1.2 and $2.7 \mathrm{~ns}$ (Table 4 ). By comparing the photophysical properties of the two zinc complexes, it is evident that the substitution of the two chlorine atoms with two electron-donor benzoate groups involves a lowering of the energy of the emitting state, an increase of the Stokes shift and, above all, a considerable increase in the emission quantum yield.
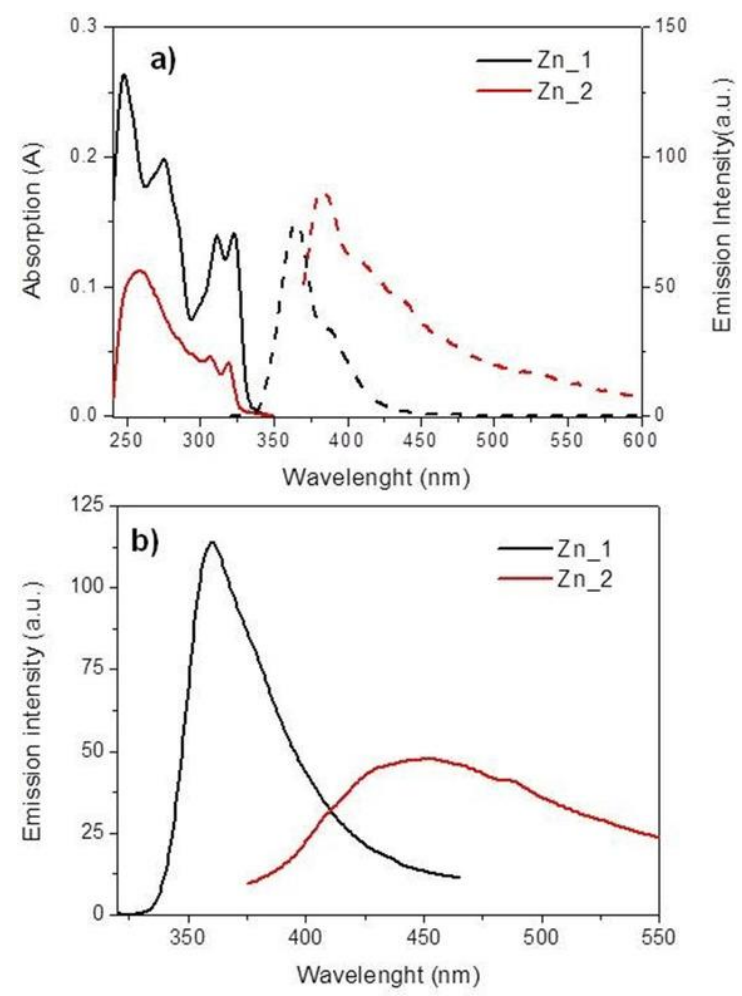

Figure 7 (a) Absorption (continuous line) and emission (dashed line) spectra of $Z n^{\prime \prime}$ complexes in $\mathrm{CH}_{2} \mathrm{Cl}_{2}$ solutions at room temperature. (b) Emission spectra of $\mathrm{Zn}$ " in the pristine condensed states at room temperature.

In the pristine condensed states (Figure $\underline{\mathbf{Z}}$ b), both samples are fluorescent. Comparing the luminescence properties of $\mathbf{Z n} \_\mathbf{1}$ in solution (Table 4) with those measured in the condensed state (Table $\underline{5}$ ), the emission maximum remains almost unchanged (365 vs. $360 \mathrm{~nm}$, respectively), whereas the quantum yield doubles from $6.4 \%$ to $15.8 \%$, and the lifetime increases from $1.2 \mathrm{~ns}$ to $78.5 \mathrm{~ns}$. This behaviour is attributable to the reduction of non-radiative de-excitation pathways that occurs in the solid phase, where the vibronic modes of the single molecule are somewhat reduced. If we compare the behaviour of Zn_2 in solution (Table $\underline{4}$ ) with the pristine condensed phase (Table $\underline{5}$ ), we first notice a consistent redshift of the emission band ( $379 \mathrm{~nm}$ in solution vs. $450 \mathrm{~nm}$ in condensed phase), a drastic reduction of the quantum yield from $24.5 \%$ to $7.1 \%$ and different kinetics of the excited-state decay: mono-exponential in solution (with a lifetime of $2.7 \mathrm{~ns}$ ) and multi- 
exponential in the pristine condensed phase, with a relevant percentage of short lifetimes (Table $\underline{\mathbf{5}}$ ). The effect of temperature variation on the photophysical properties of $\mathbf{Z n \_ 2}$ is reported in Table 8. The temperature increase (both during the first and the second heating/ cooling cycle) involves a redshift of the emission band and a decrease of quantum yield. As found for Pt_4, trends are reversible by decreasing the temperature, but the initial higher values are never restored in relation to the structural changes on first heating. The columnar structure of the $\mathrm{Zn}$ complex is indeed initially disordered, with only average distances between irregularly arranged columns (Figure SI16 in the Supporting Information), and the regular hexagonal arrangement only develops with the softening of the sample on first heating. Such a transformation clearly creates interactions between the compounds, which stabilise the excited state, as indicated by the redshift of the emission band, whereas the quantum yield decreases owing to the non-radiative deactivation increase triggered by the high temperature.

Table 8. Emission maximum and quantum yields for $\mathbf{Z n \_ 2}$ by varying the temperature. Emission maximum varies with temperature.

\begin{tabular}{|c|c|c|c|c|c|}
\hline First cycle & & & & & \\
\hline Heating & & & Coolin & & \\
\hline $\boldsymbol{T}\left[{ }^{\circ} \mathbf{C}\right]$ & $\lambda_{\max }[\mathrm{nm}]$ & $\Phi$ & $\boldsymbol{T}\left[{ }^{\circ} \mathbf{C}\right]$ & $\lambda_{\max }[\mathrm{nm}]$ & $\Phi$ \\
\hline 30 & 450 & 7.1 & 80 & 497 & 1.92 \\
\hline 80 & 478 & 4.97 & 30 & 478 & 2.98 \\
\hline 140 (isotropic) & 507 & 0.71 & & & \\
\hline Second cycle & & & & & \\
\hline Heating & & & Coolin & & \\
\hline $\boldsymbol{T}\left[{ }^{\circ} \mathbf{C}\right]$ & $\lambda_{\max }[\mathrm{nm}]$ & $\Phi$ & $\boldsymbol{T}\left[{ }^{\circ} \mathbf{C}\right]$ & $\lambda_{\max }[\mathrm{nm}]$ & $\Phi$ \\
\hline 30 & 478 & 2.98 & 80 & 493 & 1.63 \\
\hline 80 & 500 & 1.35 & 30 & 482 & 3.27 \\
\hline 140 (isotropic) & 509 & 0.50 & & & \\
\hline
\end{tabular}

\section{Conclusion}

Luminescent metallomesogens are promising functional materials for various display applications. Although considered as an emerging and growing field of research, there are still relatively few reported examples of square-planar Pt" and octahedral Ir"ll complexes being considered as outstanding emitters. This leaves space for the design of new metal-ligand systems to control the 
phase type, transition temperatures and thermal stability as well as to improve their luminescence in the mesophases.

The use of lipophilic gallate units is shown to be a good strategy in inducing low-temperature liquid crystalline properties in terpyridine-based $\mathrm{Pt}$ " and $\mathrm{Zn}$ " coordination complexes by an elegant and straightforward synthetic approach. The tpy ligand also was functionalised with a long alkyl chain, which ends with a methyl ester group, allowing further functionality derivatisation.

Only one Zn complex (Zn_2) and one thermally stable Pt complex (Pt_4) exhibited mesomorphic properties, the latter forming an original LamColr mesophase of $p 2 m g$ symmetry, for which selfassembly and a structural model were proposed and discussed.

The photophysical properties of the complexes were investigated in solution and in the condensed state. In this work, we have highlighted the role of the metal in determining the type of excited state responsible for the emission, and the role of the ancillary ligand in driving intermolecular interactions. In the case of a d-block open-shell metal, such as platinum, we have studied the role of metal-metal interactions in the formation of excited states involving the metal centre, and the steric hindrance of the ancillary ligands in directing such interactions. For Pt_1 and Pt_3 the small steric hindrance of chlorine allows a Pt-Pt interaction (already present in solution and more strongly reinforced in the solid), giving rise to an MMLCT excited state in the mesophase. On the contrary, the bulky benzoate group of Pt_2 and Pt_4 does not allow a Pt-Pt interaction, whereas weak $\pi-\pi$ interactions on the tpy ligands give rise to the formation of excimers, similarly to the solution.

Instead, in the case of a closed-shell metal such as zinc, the excited states are typically located on the ligand, so any variation of the intermolecular interactions (different in solutions rather than in the various condensed phases), which modifies the distances between the ligands of neighbouring complexes, entails a variation of the emission wavelength.

Finally, the presence of a metal centre, providing the optical properties tuning, requires great attention during molecular design, as the excited electronic states responsible for the luminescence can be modified by the supramolecular interactions that occur in the mesophase. The gallate unit, although beneficial for inducing room-temperature mesomorphism for both metal centres, is detrimental for the luminescence of the $\mathrm{Pt}$ " complexes, whereas it is more favourable for the synthesis of luminescent $\mathbf{Z n}$ " complexes. However, whereas in solution the $\mathbf{Z n \_ 2 ~ c o m p l e x ~ i s ~ a ~ g o o d ~}$ emitter, in columnar mesomorphic organisation its luminescence decreases. The great sensitivity of the metal centre with respect to its molecular environment is a potentially good property, which will be further exploited in sensing applications. 


\section{Acknowledgements}

This research was partially supported by Regione Calabria (POR Calabria FESR 2014/2020-Azione 1.2.2) through the MERAVIGLIE project. M.L.D. and G.D.M. are grateful to Dr. Angela Candreva for her collaboration in spectral acquisition. We thank the Pohang Accelerator Laboratory (PAL) for giving us the opportunity to perform the GIWAXS measurements, MEST and POSTECH for supporting these experiments, Dr. Hyungju Ahn for adjustments and help, and other colleagues from the 9A USAXS beamline for assistance. E.V., B.D. and B.H. thank the CNRS and University of Strasbourg for support. A.A.A., M.A.S., E.I.Sz. and O.C. acknowledge the Romanian Academy, Program 4. A.A.A. is grateful for an "Ion Heliade Radulescu" mobility scholarship.

\section{References}

- 1 D. Pucci, B. Donnio, Handbook of Liquid Crystals: Metal-Containing Liquid Crystals, Vol. 5: Non-Conventional, Supramolecular, Chromonic and Amphiphilic Liquid Crystals (Eds.: ), WileyVCH, Weinheim, 2014, ISBN: 9783527671403. Google ScholarSFX

- 2 Y. Wang, J. Shi, J. Chen, W. Zhu, E. Baranoff, J. Mater. Chem. C 2015, 3, 7993-8005. Crossref CAS Web of Science®Google ScholarSFX

- $3 \quad$ X. Yang, X. Wu, D. Zhou, J. Yu, G. Xie, D. W. Bruce, Y. Wang, Dalton Trans. 2018, 47, 13368- 13377.Crossref CAS PubMed Web of Science®Google ScholarSFX

- 4 X. Wu, G. Xie, C. P. Cabry, X. Xu, S. J. Cowling, D. W. Bruce, W. Zhu, E. Baranoff, Y. Wang, J. Mater. Chem. C 2018, 6, 3298-3309.Crossref CAS Web of Science®Google ScholarSFX

- 5 C. Cuerva, J. A. Campo, M. Cano, C. Lodeiro, Chem. Eur. J. 2016, 22, 10168- 10178.Wiley Online Library CAS PubMed Web of Science®Google ScholarSFX

- 6 C. Cuerva, J. A. Campo, M. Cano, M. Caño-García, J. M. Otón, C. Lodeiro, Dyes Pigm. 2020, 175, 108098.Crossref CAS Web of Science®Google ScholarSFX

- 7 A. Kishimura, T. Yamashita, K. Yamaguchi, T. Aida, Nat. Mater. 2005, 4, 546- 549.Crossref CAS PubMed Web of Science®Google ScholarSFX

- 8 Y. Wang, C. P. Cabry, M. Xiao, L. Male, S. J. Cowling, D. W. Bruce, J. Shi, W. Zhu, E. Baranoff, Chem. Eur. J. 2016, 22, 1618-1621.Wiley Online Library CAS PubMed Web of Science $B$ Google ScholarSFX

- $9 \quad$ X. Wu, M. Zhu, D. W. Bruce, W. Zhu, Y. Wang, J. Mater. Chem. C 2018, 6, 9848- 9860.Crossref CAS Web of Science®Google ScholarSFX

- 10 A. M. Prokhorov, A. Santoro, J. A. G. Williams, D. W. Bruce, Angew. Chem. Int. Ed. 2012, 51, 95- 98;Wiley Online Library CAS PubMed Web of Science®Google ScholarSFX Angew. Chem. 2012, 124, 99- 102. Wiley Online Library Google ScholarSFX

- 11 A. Santoro, A. M. Prokhorov, V. N. Kozhevnikov, A. C. Whitwood, B. Donnio, J. A. Williams, D. W. Bruce, J. Am. Chem. Soc. 2011, 133, 5248- 5251.Crossref CAS PubMed Web of Science®Google ScholarSFX

- $12 \quad$ N. S. S. Kumar, M. Z. Shafikov, A. C. Whitwood, B. Donnio, P. B. Karadakov, V. N. Kozhevnikov, D. W. Bruce, Chem. Eur. J. 2016, 22, 8215- 8233.Wiley Online Library CAS PubMed Web of Science®Google ScholarSFX

- 13 R. Bayón, S. Coco, P. Espinet, Chem. Eur. J. 2005, 11, 1079- 1085.Wiley Online Library CAS PubMed Web of ScienceßGoogle ScholarSFX

- $14 \quad$ K. Fujisawa, N. Kawakami, Y. Onishi, Y. Izumi, S. Tamai, N. Sugimoto, O. Tsutsumi, J. Mater. Chem. C 2013, 1, 5359- 5366.Crossref CAS Web of Science®Google ScholarSFX

- $15 \quad$ K. Fujisawa, Y. Okuda, Y. Izumi, A. Nagamatsu, Y. Rokusha, Y. Sadaike, O. Tsutsumi, J. Mater. Chem. C 2014, 2, 3549-3555.Crossref CAS Web of Science®Google ScholarSFX16 J. 
Barberá, I. Lantero, S. Moyano, J. L. Serrano, A. Elduque, R. Giménez, Chem. Eur. J. 2010, 16, 14545- 14553. Wiley Online Library CAS PubMed Web of Science®Google ScholarSFX

- 17 E. Cavero, S. Uriel, P. Romero, J. L. Serrano, R. Giménez, J. Am. Chem. Soc. 2007, 129, 11608- 11618.Crossref CAS PubMed Web of Science®Google ScholarSFX

- 18 M. Iliş, M. Micutz, V. Cîrcu, J. Organomet. Chem. 2017, 836-837, 81-89.Crossref CAS Web of Science ${ }^{\circledR}$ Google ScholarSFX

- 19 M. Iliş, D. Batalu, I. Pasuk, V. Cîrcu, J. Mol. Liq. 2017, 233, 45- 51.Crossref CAS Web of Science ${ }^{\circledR}$ Google ScholarSFX

- 20 M. Micutz, M. Iliş, T. Staicu, F. Dumitraşcu, I. Pasuk, Y. Molard, T. Roisnel, V. Cîrcu, Dalton Trans. 2014, 43, 1151-1161.Crossref CAS PubMed Web of Science®Google ScholarSFX

- 21 M. J. Mayoral, P. Ovejero, J. A. Campo, J. V. Heras, E. Pinilla, M. R. Torres, C. Lodeiro, M. Cano, Dalton Trans. 2008, 6912-6924.Crossref CAS PubMed Web of Science®Google ScholarSFX

- 22 M. J. Mayoral, P. Ovejero, J. A. Campo, J. V. Heras, M. R. Torres, C. Lodeiro, M. Cano, New J. Chem. 2010, 34, 2766- 2776.Crossref CAS Web of Science®Google ScholarSFX

- 23 D. Pucci, A. Bellusci, A. Crispini, M. Ghedini, N. Godbert, E. I. Szerb, A. M. Talarico, J. Mater. Chem. 2009, 19, 7643- 7649.Crossref CAS Web of Science®Google ScholarSFX

- 24 D. Pucci, G. Barberio, A. Bellusci, A. Crispini, B. Donnio, L. Giorgini, M. Ghedini, M. La Deda, E. I. Szerb, Chem. Eur. J. 2006, 12, 6738-6747.Wiley Online Library CAS PubMed Web of Science ${ }^{\circledR}$ Google ScholarSFX

- 25 D. Pucci, G. Barberio, A. Bellusci, A. Crispini, M. La Deda, M. Ghedini, E. I. Szerb, Eur. J. Inorg. Chem. 2005, 2457-2463. Wiley Online Library CAS Web of Science®Google ScholarSFX

- 26 D. Pucci, A. Crispini, M. Ghedini, E. I. Szerb, M. La Deda, Dalton Trans. 2011, 40, 4614- 4622.Crossref CAS PubMed Web of Science®Google ScholarSFX27 E. I. Szerb, A. M. Talarico, I. Aiello, A. Crispini, N. Godbert, D. Pucci, T. Pugliese, M. Ghedini, Eur. J. Inorg. Chem. 2010, 3270- 3277.Wiley Online Library CAS Web of Science®Google ScholarSFX

- 28 D. Pucci, I. Aiello, A. Bellusci, A. Crispini, M. Ghedini, M. La Deda, Eur. J. Inorg. Chem. 2009, 4274- 4281. Wiley Online Library CAS Web of Science®Google ScholarSFX

- 29 D. Pucci, A. Crispini, M. Ghedini, M. La Deda, P. F. Liguori, C. Pettinari, E. I. Szerb, RSC Adv. 2012, 2, 9071-9078.Crossref CAS Web of Science®Google ScholarSFX

- 30 F. Camerel, R. Ziessel, B. Donnio, C. Bourgogne, D. Guillon, M. Schmutz, C. lacovita, J.-P. Bucher, Angew. Chem. Int. Ed. 2007, 46, 2659-2662;Wiley Online Library CAS PubMed Web of Science $₫$ Google ScholarSFX Angew. Chem. 2007, 119, 2713-2716. Wiley Online Library Web of Science ${ }^{\circledR}$ Google ScholarSFX

- $31 \quad$ A. Y.-Y. Tam, K. M.-C. Wong, G. Wang, V. W.-W. Yam, Chem. Commun. 2007, 2028- 2030.Crossref CAS PubMed Web of Science®Google ScholarSFX

- 32 A. Y.-Y. Tam, V. W.-W. Yam, Chem. Soc. Rev. 2013, 42, 1540- 1567.Crossref CAS PubMed Web of Science®Google ScholarSFX

- 33 Y. Chen, C.-M. Che, W. Lu, Chem. Commun. 2015, 51, 5371- 5374.Crossref CAS PubMed Web of Science®Google ScholarSFX

- $34 \quad$ K. Li, G. S. M. Tong, Q. Wan, G. Cheng, W.-Y. Tong, W.-H. Ang, W.-L. Kwong, C.-M. Che, Chem. Sci. 2016, 7, 1653- 1673.Crossref CAS PubMed Web of Science®Google ScholarSFX

- 35 Y. J. Yadav, B. Heinrich, G. De Luca, A. M. Talarico, T. F. Mastropietro, M. Ghedini, B. Donnio, E. I. Szerb, Adv. Opt. Mater. 2013, 1, 844- 854.Wiley Online Library Web of Science®Google ScholarSFX

- 36 C. Oliviero Rossi, C. Cretu, L. Ricciardi, A. Candreva, M. La Deda, I. Aiello, M. Ghedini, E. I. Szerb, Liq. Cryst. 2017, 44, 880- 888.Crossref Web of Science®Google ScholarSFX

- 37 C. Cretu, A. A. Andelescu, A. Candreva, A. Crispini, E. I. Szerb, M. La Deda, J. Mater. Chem.

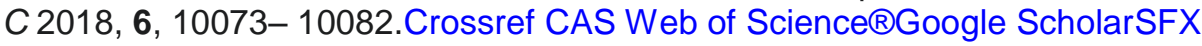

- $38 \quad$ U. S. Schubert, S. Schmatloch, A. Precup, Des. Monomers Polym. 2002, 5, 211-221.Crossref CAS Web of Science®Google ScholarSFX

- $39 \quad$ X. Yao, X. Zeng, M. Xue, L. Cseh, Y. Liu, G. Ungar, Nanoscale Horiz. 2017, 2, 43- 49.Crossref CAS PubMed Web of Science®Google ScholarSFX

- 40 G. Annibale, M. Brandolisio, B. Pitteri, Polyhedron 1995, 14, 451-453.Crossref CAS Web of Science ${ }^{\circledR}$ Google ScholarSFX

- $41 \quad$ E. I. Szerb, D. Pucci, A. Crispini, M. La Deda, Mol. Cryst. Liq. Cryst. 2013, 573, 34- 45. Crossref CAS Web of Science $\AA$ Google ScholarSFX

- $42 \quad$ C. J. Whiteoak, G. Salassa, A. W. Kleij, Chem. Soc. Rev. 2012, 41, 622-631.Crossref CAS PubMed Web of Science®Google ScholarSFX 
- 43 S. Chakraborty, P. Mondal, S. K. Prasad, D. S. S. Rao, C. R. Bhattacharjee, J. Mol. Liq. 2017, 246, 290-301.Crossref CAS Web of Science®Google ScholarSFX

- $44 \quad$ B. A. Gregg, M. A. Fox, A. J. Bard, J. Chem. Soc. Chem. Commun. 1987, 1134-1135.Crossref CAS Web of Science®Google ScholarSFX

- 45 W. J. Geary, Coord. Chem. Rev. 1971, 7, 81-122.Crossref CAS Web of Science®Google ScholarSFX

- 46 G. B. Deacon, R. J. Phillips, Coord. Chem. Rev. 1980, 33, 227-250.Crossref CAS Web of Science ${ }^{\circledR}$ Google ScholarSFX

- 47 D. Myśliwiec, B. Donnio, P. J. Chmielewski, B. Heinrich, M. Stępień, J. Am. Chem. Soc. 2012, 134, 4822- 4833.Crossref CAS PubMed Web of Science®Google ScholarSFX

- 48 D. E. C. Corbridge, E. G. Cox, J. Chem. Soc. 1956, 594-603.Crossref CAS Web of Science ${ }^{\circledR}$ Google ScholarSFX

- 49 The Cambridge Structural Database. V. Phillips, F. G. Baddour, T. Lasanta, J. M. Lopez-deLuzuriaga, J. W. Bacon, J. A. Golen, A. L. Rheingold, L. H. Doerrer, Inorg. Chim.

Acta 2010, 364, 195-204.Crossref CAS Web of Science®Google ScholarSFX

- 50 The Cambridge Structural Database. J. Zhao, I. A. Khan, F. R. Fronczek, Acta Crystallogr. Sect. E 2011, 67, o 316-o 317.Crossref Google ScholarSFX

- 51 J. A. Bailey, M. G. Hill, R. E. Marsh, V. M. Miskowski, W. P. Schaefer, H. B. Gray, Inorg. Chem. 1995, 34, 4591- 4599.Crossref CAS Web of Science®Google ScholarSFX

- 52 V. W.-W. Yam, K. M.-C. Wong, N. Zhu, J. Am. Chem. Soc. 2002, 124, 6506- 6507.Crossref CAS PubMed Web of Science®Google ScholarSFX

- 53 S. C. F. Kui, Y.-C. Law, G. S. M. Tong, W. Lu, M.-Y. Yuen, C.-M. Che, Chem. Sci. 2011, 2, 221-228.Crossref CAS Web of Science®Google ScholarSFX

- 54 G. Arena, G. Calogero, S. Campagna, L. Monsú Scolaro, V. Ricevuto, R. Romeo, Inorg. Chem. 1998, 37, 2763- 2769.Crossref CAS PubMed Web of Science®Google ScholarSFX

- $55 \quad$ X. Chen, Q. Zhou, Y. Cheng, Y. Geng, D. Ma, Z. Xie, L. Wang, J. Lumin. 2007, 126, 81-90.Crossref CAS Web of Science®Google ScholarSFX

- 56 W. Goodall, J. A. G. Williams, Chem. Commun. 2001, 2514- 2515.Crossref CAS PubMed Web of Science®Google ScholarSFX

- $57 \quad$ K. F. Bowes, I. P. Clark, J. M. Cole, M. Gourlay, A. M. E. Griffin, M. F. Mahon, L. Ooi, A. W.Parker, P. R. Raithby, H. A. Sparkes, M. Towrie, CCDC 263509: Experimental Crystal Structure Determination 2005, https://doi-org.scd-rproxy.u-strasbg.fr/10.5517/cc8v69I.Google ScholarSFX 